\title{
Get Involved: Charles Ward, Int
Materials and Manufacturing Innovation
}

\author{
Kelly Zappas
}

"Get Involved" is a recurring End Notes feature that spotlights the work of TMS volunteers and shows the wide range of activities available through TMS. This month, Charles Ward, editor of Integrating Materials and Manufacturing Innovation (IMMI), discusses how TMS members can become involved in this new open-access journal. Ward is chief of the Metals, Ceramics and Nondestructive Evaluation Division at the Air Force Research Laboratory's Materials and Manufacturing Directorate and an adjunct professor of Materials Engineering at the University of Dayton.

Q. TMS has introduced a new journal, Integrating Materials and Manufacturing Innovation (IMMI), and has named you as its first editor. How did you become involved in this project?

A. Shortly after President Obama announced the Materials Genome Initiative in June of 2011, TMS saw an opportunity to support the society's strategic technical interests and Materials Genome activities by developing a new publishing vehicle that would be the "go-to" destination for individuals and groups working in this area. I had the very good fortune to participate in a TMS ad hoc committee that validated the premise for the journal and set a vision for what the journal would accomplish. It was exciting, and rewarding, to be part of a committee defining a new way to deliver content to the community.

Q. What do you hope the journal will contribute to the materials community?

A. As the materials community becomes ever more reliant on global collaboration, integrated design teams, digital data, and computational modeling, it is clear that we need to evolve not only the way in which we disseminate ideas and information, but the format and richness of the information shared. My hope is that IMMI will help lead the way in defining a new infor- mation-sharing paradigm that can meet the demands of a growing materials community. Through its new format and topical focus, IMMI will provide the community a completely different forum to explore and advance the integration of materials and manufacturing with the design process.

Q. What kinds of papers are you looking for, and how can potential authors submit their work?

A. We're looking for papers that address the key challenges to truly integrating the materials, manufacturing, and design engineering processes. This includes topics on handling data, experimental and computational techniques, verification and validation, and case studies of engineering problems that were approached with integration in mind. Interested authors will be able to submit their articles, animations, data, and models on-line at www.immijournal.com. Since IMMI is seeking to reach across traditional discipline lines to support an integrated engineering approach, I'm very hopeful we're going to attract diverse input and perspectives to the journal.

Q. What will be the benefits of the Open Access format for authors?

A. Open Access means that everyone in the world will have on-line and free access to all journal articles appearing in IMMI. Of course, the digital format will also give us a lot of flexibility to explore new and quicker means of content delivery. For example, we're particularly excited about the ability to post digital data and models, which will be archived with the parent article. We're confident these features will not only meet the intent of providing greater dissemination of more complex information, but will provide an easy means by which data and models can be cited by other authors. As the journal matures, we'll be looking to expand the types of digital information presented and how it's integrated into the journal article itself.

Q. Why would you encourage TMS members to get involved with this new publication?

A. As we continue to move down the path of greater global interconnectedness both in a social and engineering context, IMMI is poised to support the needs of the community with a new perspective on publishing. I feel both the IMMI subject area and its publishing approach are natural responses to the needs of the broader engineering community. I think TMS members will find that what IMMI offers the community complements the increasing interdisciplinary expectations on our profession and will provide them with a unique outlet for their work.

Kelly Zappas is a contributing writer for JOM. 